\title{
“Others” Inside the Invisibly Walled World—Chinese Rural Cultural Identity Crises*
}

\author{
LIU Juan \\ Renmin University of China, Beijing, China
}

\begin{abstract}
This article explores the identity politics and crises of rural cultural identity in Chinese "walled" practices of urbanization and its modernization, which is not signal but a core of stability. Here, this topic was situated within historically specific modernity developments and practices which have disturbed the relatively "settled" character of rural cultural identity, above all in relation to the process of urbanization in China. Though rural people seems to have a common rural origin, they actually encountered with unprecedented cultural identity crises - the questions of becoming rather being: not "who they are" or "where did they came from", but "what they might become" and "how they might represent themselves" during their way to modernization and urbanization. The above questions constitute the content of this paper.
\end{abstract}

Keywords: rural cultural identity, modernity, urbanization, history, "others"

\section{Introduction}

During the quick urbanization and modernization process in China, the issues - the mobility and openness of society, and consequently what are inherent in this issue promote disorders and crises of rural cultural identity - must be reconsidered. To explain these issues, some Chinese scholars put forward a fundamental assumption that rural cultural identity is being undermined by Chinese modernity and the process of economic-political urbanization (Hu, 2009, pp. 69-73; Wang, 2010, pp. 14-18), but many articles take given conditions of present for granted. This paper will attempt to answer the questions that have been posed. First, I try to examine the condition in terms of invisibly walled world, also about cultural identity crises, which acted as the real focus role in Chinese rural social crises. I do not mean to suggest that the rural cultural identity is the essential core of the entire rural society; nor am I saying that it would be impossible to approach the reasons of rural cultural identity crises by other routes than the "walled" practices of modernity. Secondly, in order to get a better understanding of what are rural cultural identity crises and why, I want to ask the question "how is it going on". Rather than asking what in a given condition, but ask how it is going on and how rural people are affected. In short, I plan to discuss the practice of rural cultural identity crises: to show its origin or, more exactly, to show "how and why do they happen", to show "what are their effects and how do we do?"

\footnotetext{
* Fund items: This work is supported by the National Social Sciences Fund Major Project "Sino Russian Media Communication, Strategic Communication and Global Governance in the Construction of Institutional Discourse Power" (No. 16ZDA217) and also is supported by the Beijing Social Science Fund "Research on the International Communication Strategy of the Construction of the Silk Road Economic Belt" (No. 15ZDA07).

LIU Juan, Joint Ph.D. candidate, School of Journalism and Communication, Renmin University of China, Beijing, China; Department of Communication, University of California San Diego, San Diego, USA.
} 
From a theoretical viewpoint, this study aims at investigating the role of Chinese urbanization and modernization in (re-)defining and transforming rural people's cultural identity. The works of some prominent Chinese scholars on rural questions show that although the existence of the urbanization as the pre-condition of redefinition of rural cultural identity is widely accepted, the relationship between the urbanization and rural cultural identity has not yet been investigated in depth. A new perspective from which to consider the rural cultural identity will be proposed in order to take into account the continuity of its tradition and modernity, that is, exclusive-inclusive, old-new, inside-outside (He \& Xue, 2014, pp. 131). Indeed, for rural people to exist, it is presupposed that there are some other communities, some other identity resources, which they can use to define themselves. Rural people thus have to understand and define themselves in a dual (even pluralism) relationship between modernity and tradition rather than in a single-exclusive and self-evident way. Moreover, I shall argue that the cultural identity crises of rural people can be solved by their autonomy in a mutual-continuing way rather than only through invoking Chinese traditional rural culture.

This section will be complemented by a case-study of Beijing government's policy for rural people. I shall thus seek to illustrate the ways in which the rural cultural identity may be conditioned, deconstructed, and transformed by the presence of invisibly urban walled world. Thus, the crises and redefinition of rural cultural identity will be highlighted in the background of modernity and urbanization.

\section{What Are the Rural Cultural Identity Crises?}

"Identity is the totality of one's perception of self, or how we as individuals view ourselves as unique from other" (Bhugra \& Becker, 2005, pp. 18-24). Hall (1990, p. 222) notes that "Cultural identity is collective or true self hiding inside the many other, more superficial or artificially imposed 'selves' which a people with a shared history and ancestry hold in common". So, "The components of cultural identity include religion, rites of passage, language, dietary habits and leisure activities" (Bhugra, 2004, pp. 1-13). It can stabilize and guarantee an unchanging "oneness" or cultural belongingness underlying all the other superficial difference.

However, this collective self with a common history or ancestry was deconstructed by urbanization and modernization. Both of them set an invisible wall for the rural people through disavowal and deny, although the rural people and the rural area were integrated (either voluntary or forced) into them. Modernization and urbanization signify the capacity to deconstruct at least aspects of a given identity and imply the deconstruction of past forms of life, values, and identities. "But it is a paradoxical unity, a unity of disunity: it pours us all into a maelstrom of perpetual disintegration and renewal, of struggle and confrontation, of ambiguity and anguish, all that is solid melts into air" (Berman, 1982, p. 15), resulting in cultural identity conflicts. Just as Douglas Kellner (1992, pp. 141-143) said, "Identity continues to be the problem it was throughout modernity, far from identity disappearing in contemporary society, it is rather reconstructed and redefined". This radically shifting process, however, is likely to provoke rural people's feeling of anxiety and fear: the essential questions about "what do they want", "who do they want to become", "where do they want to go", and "how do they self-define and self-understand, namely how do they set their presentation of themselves on the way to modernization?" These questions reflect a basic present fear about the mortality of the traditional collective culture identity, which is becoming unstable and unsolid.

There is also the fear that every traditional thing, just as moral principles and cultural meaning, is continuously melted, dispelled, and dissolved by liquid modernity (Bauman, 2000, pp. 5-6). In defending against such a catastrophic event, Chinese government refreshed the perennial summon of "Chinese dream", 
symbolic representations, ancient gala signifiers, and traditional myths concerned with an "illusory perpetuation" and "immortal meaning" through different culture policies, especially by incorporating modern elements into the rural culture. In terms of connecting them, Chinese government tries to defend identity of rural people through facial changes against the reality of fragile identity. There is, indeed, a kind of slow accretion of living mortality in rural culture identity that does not acknowledge the possibility of its own deadness. For instance, rural people find that the arrival and prevalence of consumerism and hedonism had an absolutely sterilizing or, rather, anesthetic effect on them, because they felt this kind of modernity culture had an implacable logic that left them no possible room for emancipation.

The consumer culture (one important part of the modern culture) in general is one of exclusionary politics. An overwhelming number of rural people are forced to live with a sense of deprivation arising out of their inability to match up to the consumer lives and identities of their urban reference groups (Mathur, 2014, p. xxix). Following this, it is Chinese rural people that do not creatively and effectively deny the logic of modern culture, leading to their cultural identity autonomy being undermined. Thus, the instituted and historical rural cultural identity is undergoing the potential mortality; there are being exiled or being nomadic state without a solid security in their identity world.

Chinese rural people were totally integrated into the modernization machine through the media, capital forces, and political urbanization. They overturn the solidity and legitimacy of rural institutional culture, then challenge the traditional identity-common village, common political values, clan system, and shared relationships, which underpins rural community. Only if little things are constantly changed, and at least certain things cannot be continuously replaced by others, can rural people maintain their identity. Then, it is clear that the modern problem of identity is not only how to maintain it stable and solid, but also offer other alternatives for people. So, it is time for Chinese government to consider how to unify the relationship between "traditional inheritance" and "modern trends" in the sphere of "identity" (Zhao, 2007, pp. 55-63).

So, rural culture identity crises could be classified into four categories: internal fragmentation and confrontation, disavowal of rural traditional culture, xenophobia over urban culture, cast doubts on official/political mainstream culture. First, precisely because cultural identity is constructed within specific social context through difference (Hall \& du Gay, 1996, p. 14), then they are products of the fragmented Chinese society and are the sign of an internal conflicting rural world. It goes without saying that the internal fragmentation and confrontation characterized them, including contradictions between rural elites and the general public, also including differentiations inside ordinary rural people (Hu, 2009, pp. 69-73). In terms of xenophobia over urban culture, the migrant rural people crowded into big city not only for survival but also for development rationality; they sought to integrate into urban culture and tried to take roots in urban space (Zhang, 2004, p. xi). But their illusion was broken down by urban rejection: institutional exclusion, cultural exclusion, economic exclusion, and symbolic exclusion, and they were regarded as stigmatized strangers — dirty, poor, churlish.

Consequently, there is a paradox feeling in rural people's mind: hate-love, namely xenophobia toward urban. Contrary to this repulsive force is the pullback power from rural traditional culture. As a native rural people, they do not acknowledge millennium rural collective memory and tradition heritage that used to be the basis for constructing social integrity and strengthening Chinese social cohesion. These traditional culture have been devalued as modern notions of "backwardness", "feudalism", "superstitious", and "foolish" (Cohen, 2005, 
p. 3), ranging from clothing style, local language, to human etiquette, folk beliefs, customs and values ( $\mathrm{Wu}$, 2015, pp. 10-12). In terms of official mainstream culture, Marxist ideology is undergoing a big crisis. Most rural people, especially young rural people, cast doubts on them and try to replace them with foreign popular culture and consumerism values (Chen, 2011, pp. 41-43).

These are what we describe rural culture identity crises. "Identity as the agreement between public value and private self-assertion must be completely re-thought in terms that are contrary to historical forms" (Hoffmann-Axthelm, 1992, p. 200). Hence, the greatest tension and anxiety for the modern rural people is not the issue of economic and technological achievements, but the issue of cultural identity (Zhang, 2006, p. 5).

\section{How Do the Rural Identity Crises Happen?}

When we acknowledge these crises, we must point out that rural modernity defined itself against the traditional culture, which remains the essential, albeit never the sufficient, condition of self-sustaining: the rural community members differentiated themselves from the "traditional moral artifice" and "modern order" that the government posed on them, and then put themselves in a dilemma. The narrative of how this dilemma became imprinted on to a geographical polarization - with the dynamic urbanization distinguishing itself from the static and immobile rural land - is now a familiar one. "It is not just that, increasingly, many people have no roots; it's also that they have no soil" (King, 1991, p. 6). "Individuals who migrate experience multiple stresses that can impact their mental well being, including the loss of cultural norms, religious customs, and social support systems, adjustment to a new culture and changes in identity and concept of self” (Bhugra \& Becker, 2005, pp.18-24). The same to rural individuals' migration into urban involves the loss of the familiarity, including values, family networks, and social structures.

Under this dualistic dilemma, Chinese community not only was divided into the benighted (the rural area) space and the enlightened (urban society) space, but also was separated into visibly walled world (economic-politic) and invisibly walled world (psychological-psychic). The enlightened (city) defined the benighted (the rural area) as the "Others" who was remote and alien to urban modernity and its great goal of transformation. The invisibly walled world (a denial mind and a disavowal attitude from urban people) works together with the visibly differentiated world (economic and political inequality) to define rural people as "outsiders" who have been inside and weaved into urbanization network. Rural community members thereby were refused by urban modernity in terms of essence. In this cultural context, the dilemma of the modern-rural world was a painful one (Wang Chuanguang, 2001, pp. 63-76). On one hand, big city refused to embrace rural people, especially the low-class rural people, even though it cannot maintain its order without them. On the other hand, it was impossible for rural community to deny new cultural "dynamic" (most are consumerism culture) coming from big urban city, which now is embedded into rural people's daily life (Wu Licai, 2011, pp. 78-84).

Above facts can be illustrated by the following figures. As we can see from the Figure 1 below, the size of urban area in China has increased by 18\% from 2001 (38\%) to 2015 (56\%), while, the pie Figure 2 tells us Chinese urbanization rate has increased almost twice (increased from $36.22 \%$ in 2000 to $61.55 \%$ in 2017). We can clearly see that there is a stark contrast within past 16 years. This increasing urbanization rate means more modern buildings and transportation system (there are 1.27 million kilometers newly built rural highways by March 5, 2018), and means more modern lifestyle. 


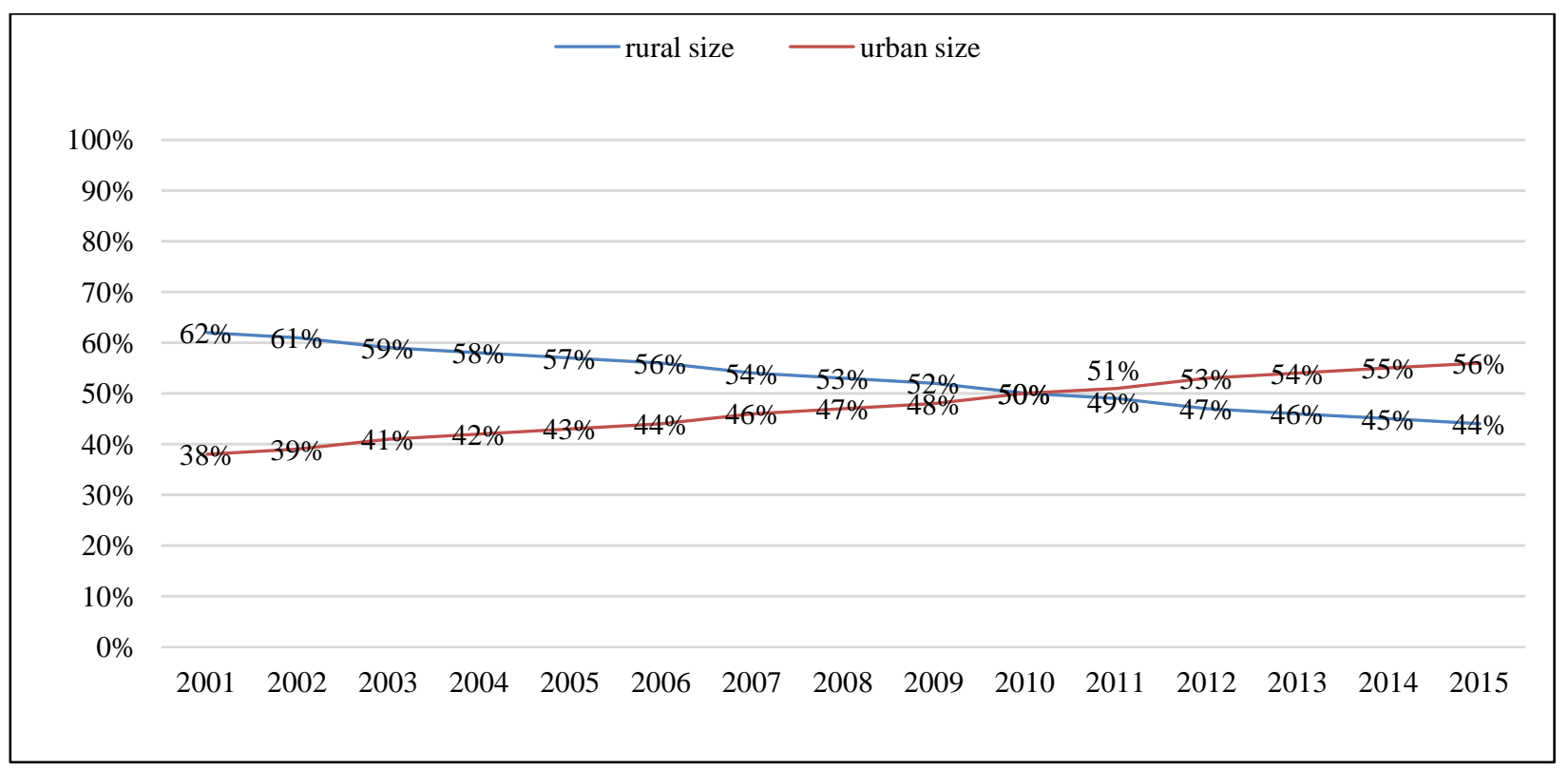

Figure 1. Urbanization data in China (2001-2015) ${ }^{1}$.

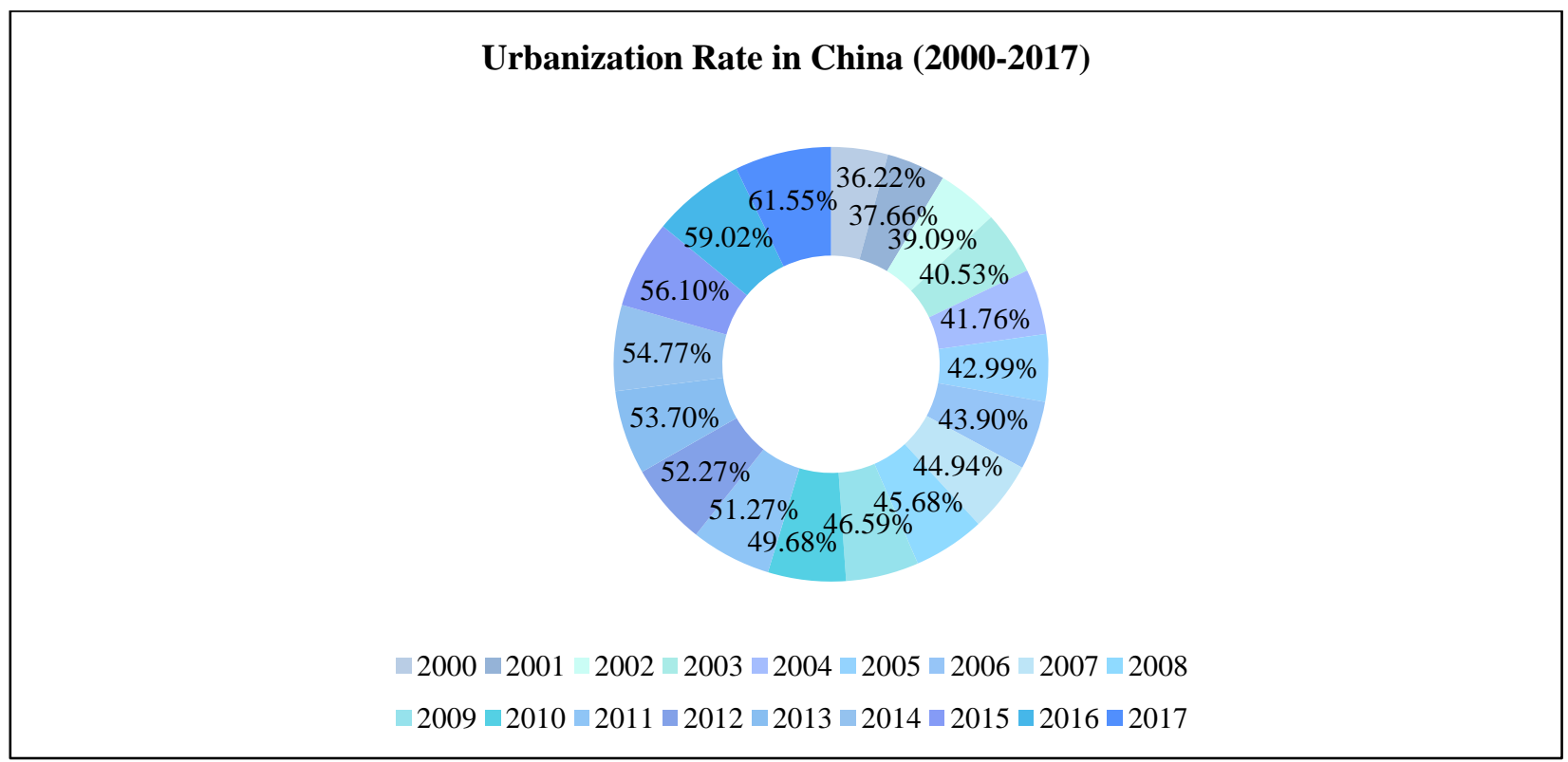

Figure 2. Urbanization rate in China (2000-2017) ${ }^{2}$.

Especially, we know that the mileage of high-speed railways increased from more than $9,000 \mathrm{~km}$ to $25,000 \mathrm{~km}$, accounting for two-thirds of the world. ${ }^{3}$

Indeed, the achievements of China's urbanization in recent years triggered yearn and desire of rural people, if also trepidation. The stunted-rural cultures felt the impulse to emulate urban modernization; they must redefine and reset themselves on the course of urbanization and modernization. There was an urgent passion to change, but the experience, we know, was rarely an appropriate one. While the economical and social

\footnotetext{
${ }^{1}$ http://data.stats.gov.cn/swf.htm?m=turnto\&id=432.

2 http://news.ifeng.com/gundong/detail_2013_03/01/22616053_0.shtml.

3 http://news.163.com/18/0305/09/DC4GMNRL0001875N.html?baike.
} 
arrangements of urbanization were mapped onto rural land, its dynamic essence (creativity and autonomy) was invariably absent. Regardless of whether it was voluntary or mandatory, the overall absence of such a dynamic, or its merely desultory operation, has maintained the modern arrangement of all regions in China's transition distorted. The efforts of mimicry were rarely transformed into authentic modernization, which may be a specious, phantasmal modernity and urbanization; their essences were erased out, leaving some facial items, such as luxury hotel, splendid shopping mall. The exposure to these modern culture machines resulted, not in value emancipation and spiritual void, but in consumerism, hedonism, nihilism and fetishism. This was the consequence of an excessive openness and over-urbanization (Zhao, 2006, pp. 31-36), resulting in "suffering feelings of guilt over abandoning culture and homeland and feeing painful if memories of the past begin to fade" (Bhugra \& Becker, 2005, pp. 18-24).

Meanwhile, there were fearful feelings that the disintegrating and dissolvent principles of urbanization would be fatal to the rural historical culture. Urbanization threatened rural traditions, especially traditional culture heritages. Consequently, there was cultural reaction from rural community, involving the reemphasis of traditions and origins again.

There was reversion fashion to the ancestral and blood authenticity, which, like other forms of essentialism and sameness, assumed a cultural identity that is "self-identical" and "self-evident", essentially continuity over time, and posited itself in essential distinction from other historical subjects in order to rebuild common-shared cultural community. (He, 2011, pp. 36-37)

But, of course, the ancestor cannot wake up; the past cannot be recovered as it is; the coherence of the rural culture identity cannot be reconstructed. This conservatory and compensating return to traditional culture actually indicates "a rely on the past", to compensate rural meager modern culture by facially reviving and remembering historical culture. In this dependency, too, as in the economical and technological dependency on the modernity, there is an erasure of real personality and an obliteration of true feeling structure; in both cases, "a borrowed culture order, a borrowed life; a borrowed mind, a borrowed feeling" (Hall \& du Gay, 1996, p. 10).

There is a choice; it seems, between a reversion to the authenticity of (ethnic or ancestral) origins and assimilation of an external modernity. It is a ridiculous choice, a spurious choice. It was the choice that the urban and government imposed, resulting into a schizophrenia at the heart of the rural people's cultural identity, which is symbolized as a wounded mental order and spirit chaos. This is an unacceptable condition for the Chinese government; they initiated many cultural revival measures, such as launching out various "Shehuo" activities (the traditional gala for worshiping ancestors) during festival days. This prevalence of Chinese folk gala is a continuation of an ancient tradition of offering sacrifices to Land God and Fire God. But we need to unfold the essence inside the questions: What are the possibilities for transcending this either-or choice? We must be concerned with those developments, both culture and mind, that have potentials for destabilizing and deconstructing this dual logic.

There is an increasing awareness of what we can describes as the "dilapidation" of the urban project and ideals (this is surely what the debate around rural cultural identity must be care about). Empty of meaning and significations, urban and modernity indeed exercise an efficient influence on the rural cultural identity. The question is whether it will lead to cultural austerity and xenophobia (internal or/and external), or whether it is possible to rebuild the autonomy of rural cultural identity on a new basis. Besides, there are concerns about issues of the creative transmission of cultural identity and universal values construction, on the basis of 
consensus between different rural communities and cultures. If there is any form of solidarity that can provide a foundation for a truly universal consensus, it is surely a new cultural solidarity. Therefore, it is imperative for connection between those pursuing similar constructive goals out of their different experiences. Progress can only be achieved through cultural reciprocity and acceptance. At this point, we'd better to move from thinking in terms of rural culture identity to considering the significance of culture creativity and culture autonomy. In Xudong Zhang's (2006, p. 3) words: We have to be ready to transcend our tradition, to think in terms of updated tradition in a modern-tradition continuity.

These preliminary ideas are still abstract and disengaged because they come from intractable realities of actual cultural encounter and identity. How do we give them some substances? What does this mean in a specific context? In the following sections, I want to consider the issue of cultural experience and rural cultural identity, especially through a case study of the relationship between rural cultural identity and modernity in Beijing. First, we shall have to consider the resentment against the rural in fear of resources scramble and cultural fragmentation. The projections of the urban psyche have been, and remain, fundamental obstacles to cultural encounters and understanding.

Also, I intend to examine the reality of rural culture with special consideration to its urbanization orientation and modernity context. I shall consider the nature of its assimilation of modernity, especially in the period since the Chinese government introduced the rural urbanization policy. Then I shall examine recent developments, involving the resurgence of repressed factors of the urban culture, and strive to construct an alternative form of modern rural identity. Finally, I come to the question of what the changing identity of rural people might entail for its relation to modernity. The question, really, is whether cities can truly open its door to rural people. Coming to terms with rural identity is a pivotal factor of the identity reordering and re-association that must be undertaken in the urban space.

\section{"Inside" Rural People Are Homeless-A Case Study}

After 2018 spring festival, a cluster of rural labor force with their dream crushed into the big city. Most of these immigrants were youths whose age are between 18-35; they stepped onward "labor" train to Beijing at cost of the wholesale abandonment of their traditional rural way of life, likening it to a "spiritual conversion". This "spiritual change" brought by geographic change triggered the question of cultural identity: Rural youths are trying to be admitted as full members of Beijing in order to escape from the terrible position of being its pariahs. In certain respects, some of them have successfully established their credentials in Beijing urbanized and modernized society (albeit at a psychic cost). Among native Beijing citizens, however, they have remained the sense that rural people are not authentic Beijing citizens, even though rural people have bought house and have a perpetual residence right there; they also have the sense that rural people are alien, outsiders, interlopers in the Beijing community. Most rural people work in Beijing, but they cannot afford the goods in Wangfujing Mall (a luxury shopping mall in Beijing). Therefore, they live inside Beijing physically but mentally outside, namely rootless.

Figure 3 shows us the changes of the migrant population of Beijing (lived there for more than a year). From 1980 to 2015, the amount of migrants that lived in Beijing has increased more than 45 times. From 2000 to 2015 , there has been a rapid increase of 6.068 million people, which is close to $36 \%$ of Beijing's total population (at the end of 2015, the total population of Beijing was 21.705 million). 


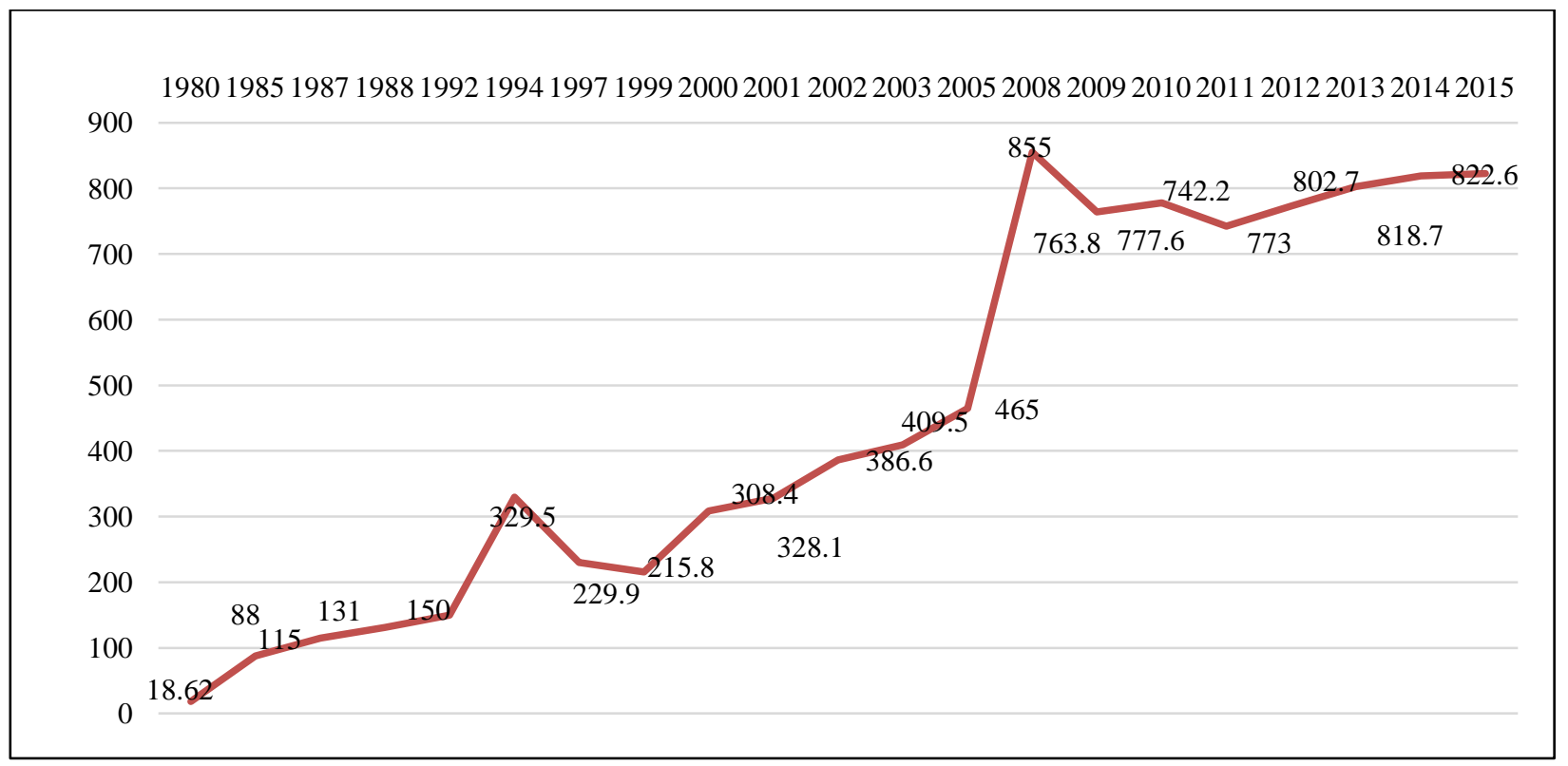

Figure 3. The trend of migrants of Beijing (1980-2015).

Although rural people have found a certain accommodation within Beijing order, they changed their clothing style, their behaving and speaking modes. In the accelerating growth of Beijing, rural people are seen as vital assets and they are basic labor force for Beijing low cost and high speed development. The rural people must continue to be accommodated because of their significance for whole economical development (Long, Zou, \& Liu, 2009, pp. 454-462). But this economic significance does not translate into cultural and political acceptance. Most significantly, in this respect, rural people's application for membership of permanent residence in the urban area (like Beijing, Shanghai, Shenzhen) is rigidly restricted and limited, so most rural migrants are not granted permanent household registration right in these cities and only registered temporarily (Long et al., 2009, pp. 454-462). It is estimated that by 2002, there were around 150 million rural residents who worked in the urban areas without permanent urban residence qualifications (Zhang, 2004, p. x). "They lack a sense of belonging to the city - where they sometimes have lived and worked even for a long time-for a number of reasons that include institutional forms of exclusion and socioeconomic marginality" (He \& Xue, 2014, p. 132). Rural people are not so much stranded at Beijing doorstep, but confined to the servants' quarters in Beijing. Their accommodation is a definitely precarious one. Take the data in 2014 as an example.

From the figure above, we can conclude that: The migrants occupied the low end of the social-economic chain in Beijing, especially most of them were in the services industry. The differentiation and integration may occur concurrently which should hardly come as a surprise (Cohen, 1991, p. 121), which is the same to China within the context of complex and paradox modernity. Despite its great proportion of $67.6 \%$, the service workers (mainly business service) as a main part of migrant populations were treated as exclusive outsides in reference to the status and role of Beijing residents. They are mainly concentrated from community services

\footnotetext{
${ }^{4}$ Data (1980-1984) are from Beijing Municipal Bureau of Statistics, Beijing Survey Corps, China Statistics Bureau (2006), p. 73, Beijing Statistical Yearbook 2006, Beijing, China Statistics Press; data from 1985-1988 are from Beijing Population (Beijing Volume), p. 188, China Statistics Press, 1994; 1997 is an extrinsic census data; from 1999 to 2003, it is the monitoring data of the Beijing Municipal Bureau of Statistics on Migrants; from 2008 to 2010, the data come Beijing's population mobility and rental housing information platform; data from 2010-2015 are from the Beijing Yearbook. https://wenku.baidu.com/view/b4d155dd5901020206409c14.html.
} 
(occupying 15.3\%), repairing services and other relevant services (20.5\%), to wholesale and retail trade services (accounting for 18.3\%), hotel and catering industry services (13.5\%). Obviously, rural people (as the main part of migrants) are in the low end of Beijing social ladder, and they do not have the right to basic social welfare and economic opportunities reserved for the permanent urban residents (Shen, 2002). "Low-rural" population not only was not accepted within Beijing society but also was not really integrated into the essential aspect of social and political life there. It will be seen that the living conditions and social status of this group are at a relatively low level. Despite this, Beijing government promulgated the policy of expelling low-class population and forced them to move out Beijing after a fire accident in a group-shared house in the winter of 2017.

Another case is the Picun question. Picun is a village located outside the center of Beijing and has more than 20,000 migrant workers from the rural area. Most of rural people lived there without basic rights. Their children do not have rights to enjoy official school education, just are educated in their self-organized school. This suggests that rural people have not yet sufficiently to be accepted by modern urban city, or that they have not thoroughly alleviated their identity crises in favor of urban modernity. They left their home for city, and became in-betweens and homeless both in body and soul, resulting in the "uncertainty and anxiety of identity" in their feeling structures. Namely, they no longer want to stay at their villages as a farmer, but cannot be recognized and accepted by cities, and then they turn into actual homeless outsiders. They are treated as an "in-between" people, and their compromise still does not conform to urban standards.

Beijing government had lots of fundamental grounds for objection: The rural people are not rich, and they are not high-tech skills workers. This embodiment is the arrogance of Beijing attitude. For those opponents, there is some essentially anxiety about resources scramble and space contention. There can be no possibility of rural assimilation into the urban society and there can be no possibility of urban acceptation of the rural people. It was the contempt and indifference exhibited by the Beijing power towards the new rural migrants: Rural migrants assimilate Beijing values and standards, alongside the conviction that, despite whatever they try to do, it will be impossible for them to succeed. Therefore, problems would be brought by above situations: (1) problems of origin, the attachment of a peasant community to basic group, rural migrants left their home to urban no longer tied to their family and their land; (2) problems of connection, succession, historical link, and sociological causality; (3) in-between dilemma place, their community is no longer autonomous, being involved in many ways with the whole economy (Lefebvre, 1970, p. 288).

A young Sichuan journalist who has bought her house with her husband in Beijing said: Although I have a Beijing house and a permanent residence ID, but I am not accepted by my native Beijing friends and it reminds me that I am an outsider; however, it is obvious that I cannot find a root in Beijing. Then, I love Beijing with a paradox feeling, love with hate, intimate with alien. "In addition to this alienation in the city, they are deprived of rural land back in their home village, which threatens their rural identity and rural livelihood" (He \& Xue, 2014, p. 132). This case shows how far it is possible for rural people to build their Beijing modern cultural identity, yet still be rejected. Moreover, it also shows how cultural-political exclusion can be turned into identity hatred. There is a sense of being overwhelmed by an alien culture, Beijing xenophobic attitudes towards the seasonal rural labor force, running the risk of becoming a "chilly" city. Lots of rural workers were treated as pariahs. Urbanization demands a sacrifice but does not accept it. The "in-between" rural people simply show their dilemma to pursue urban elusive modern culture, yet it still is rejected and derided. 


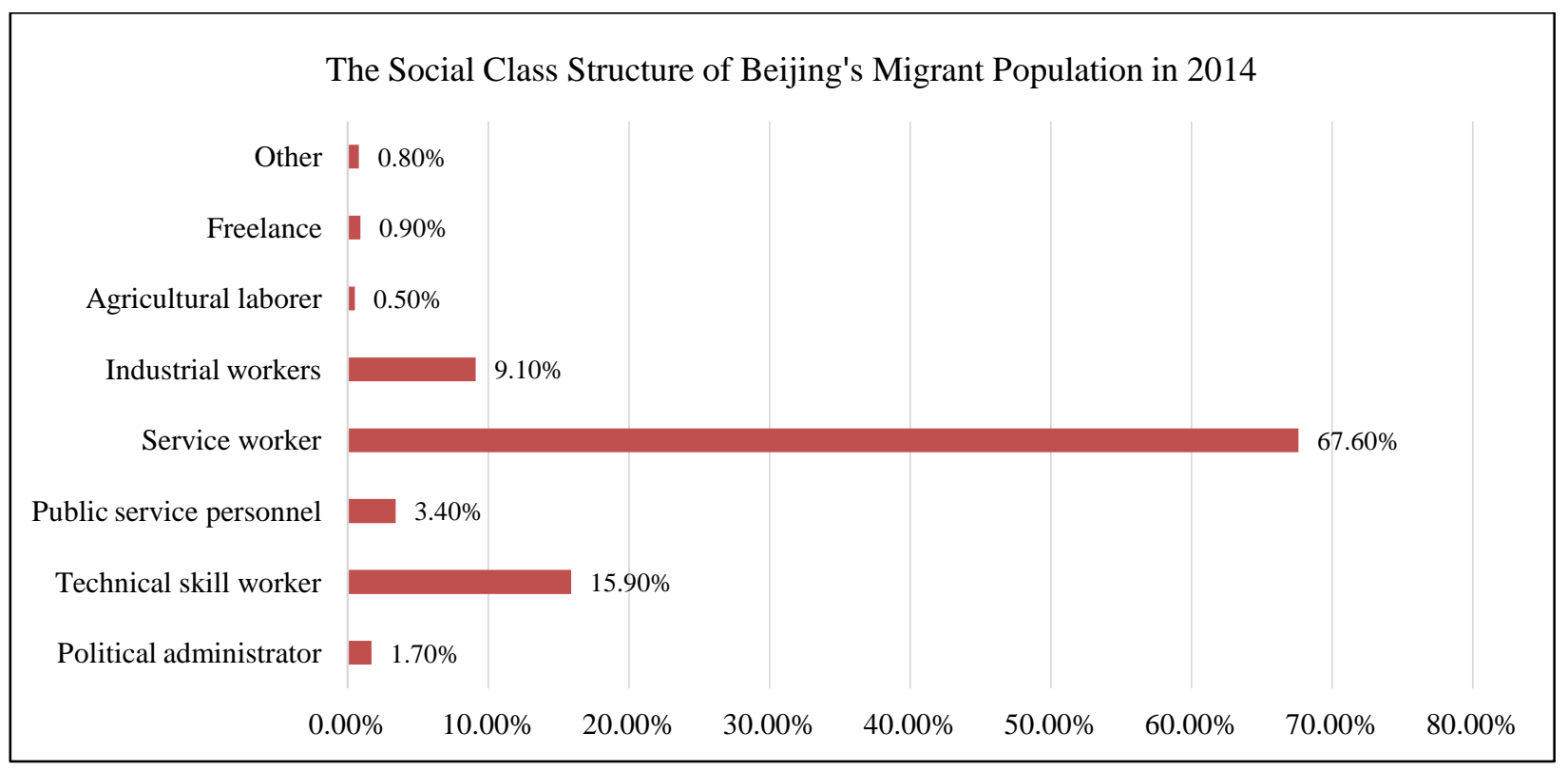

Figure 4. The social class structure of Beijing's migrant population in $2014^{5}$.

\section{A Void-Arid Identity}

Now, I turn to consider the consequences of urbanization within rural identity. Rural people made their sacrifices for modern achievements; they promote urbanization process. Also, they opened themselves unconditionally to the "hug" of modernization. The facts suggest that urbanization requires a fundamental transformation of cultural identity of the rural people, which is because urbanization is conceived as the road to "redemption" for the rural poverty, and its adoption was complete.

What has been achieved? What kind of identity and culture have been renewed and instituted in the rural people heart? Rural peoples' modernization has been an empty and arid affair. "A consequent lack of an adequate social support system, a disparity between expectations and achievements and a low self-esteem may result from a dissonance in culture between the individual and the surrounding population" (Bhugra \& Becker, 2005, pp.18-24). The map of Chinese modernization is already in designing, but anything resembling a modern dynamic has been lacking. In this respect, the big reluctance to acknowledge rural people as genuinely urban citizens has a certain justification (what is utterly unjustifiable, of course, is that the urban advocate a unique logic of "development" as the only possibility; its inability and powerless, that is to say, to imagine modernity on the basis of any other sense of urbanization). Rural culture has been derivative and imitative in its emulation of the modern model (Wu Licai, 2011, pp. 78-84). Rural culture transformation brought by this modern model is too shallow and lacks creative richness.

Seemingly, cultural identity and meaning are created only through reference and conform to the urban ideal: Rural politicians constantly measured their achievements based on their simulation and resemblance to the urban model (or, rather, their real core of what it is). Therefore, rural culture development is consequently to be understood from the perspective of more effective counterfeiting or mimicking of the urban paradigm. But, of course, however vivid the emulation, it does not equal to the authentic thing. There has been a creative void at the heart of modern rural cultural identity, resulting in internal fragmentation and external hatred of the

\footnotetext{
${ }^{5}$ http://www.doc88.com/p-6734560512491.html.
} 
official cultures. Rural culture casts the old and official order into doubt, but it cannot use this process to emancipate new meaning of a creative kind. It was an ersatz modernism that supplanted rural traditional cultural identity.

It would be possible to fabricate rural stories in terms of openness to urban, and from the perspective of the vicissitudes of cultural assimilation and development. Alternatively, we could interpret it as a narrative of disavowal, repudiation, and denial. In terms, that is to say, of that it is rural cultural identity that stifled itself. This is the real of topic that we shall pursue here. For rural politicians, it seemed as if the principles of modernity could be accommodated only on the basis of the massive interdiction and prohibition of the historical and traditional culture. In order to make way for new modern values, rural culture had to be purged of its mystified and ancient lifestyle. In order to become "civilized", it must purify itself of all that was superstitious, and by that token pre-modern, in the traditional culture (Sun Feijuan, 2009, pp. 71-75). What this resulted in was not only differentiation and fragmentation of collectively historical memory, but also, and even more problematically, disavowal and suppression of the rural culture autonomy and social creativity. As much as it has been shaped by the assimilation of urban culture, rural cultural identity is still a product of various disavowals: Rural society has been conducted and practiced in the technique of fragmentation and repression.

The rural past was disdained and despised for its falling behind the modernity, especially its traditional family beliefs and morality. Besides, rural ancestral heritages were also condemned as the source of all obstacles. The new rural people initiated a series of intensive reforms, and intended to nullify and eliminate the historical heritage, especially after the prosperity of social media such as Wechat, Kuaishou and Douyin. These goals were aimed pre-eminently at secularizing of rural cultural identity (demolition of ancestral church halls, disestablishment of the psychical tombs, dissolution of dervish orders, etc.), and also indicated momentous changes of daily lifestyle (establishment of modern-rural villa, adoption of networks, prohibition of ancient rituals). The interface between politically driven goals of power and reform, the preservation of a nation's cultural heritage is problematic for China (Sofield \& Li, 1998, pp. 364-364). These reforms maintained that the new rural cultural identity has a weak tie with the old. What was being attempted by the rural cultural identity was no less than the effacement of the tradition. The new cultural identity derived from this fundamental negation: The rural people were envisaged as an independent and autonomous substance, but in seeking their anchor points, they were lost and could not find themselves, since their past and history was annihilated. It emerged as a rural cultural identity without history and continuity (Wang Chunguang, 2001, pp.63-76).

What was at issue, however, goes far beyond a disavowal and closure of the past: The rural cultural identity was also formed by suppressing contemporary reality in the new society. In so far as they were-and could be nothing other than - products of history, contemporary rural cultural identities were themselves problems for the traditional rural regime. The rural people committed themselves to eliminating the true rural cultural identity that seems to perpetuate a new modern one and abandon an old one. Their endeavors were being undermined in a number of respects, impeding the vigor and creativity necessary to maintain a unified cultural identity.

The rural cultural identity has been characterized by the spirit of modernity, by ethic, lifestyle and morality interaction and mixture. The rural society that emerged from its negation of tradition was fundamentally opposed to its real identity. It resolved to establish a new world without past, and subsequently self-defined through cultural imitation and assimilation. The enormous rural cultural heterogeneities and diversities were regarded as inimical to the realization of modern sameness and urban consensus. New rural culture pursued the 
goal of one-dimensional modernization and consumerism. It reacted to its own history as immanently centrifugation, seeking to reconstruct the culture by means of a confrontational principle of lifestyle homogenization and a unified assimilation, which aimed to transform rural cultural identity through modernity, and to connect the concept of identity with that of social-economic integration.

In many cases, the new rural people had forgotten their history. Ancestral attachments and historical feeling structures could no longer be accepted and admitted, and the cohesive spirit anchor could no longer be free from fragmentation. Not only were these real identifications suppressed, but the point is that their very actual reality came to be differentiated and negative. Rural attachment was also conceived as a shame, and also was considered to be a threat to the process of culture creation. Urban ideology was regarded as a secular and new alternative, conforming to the values of the "modern world": a transformation in values, offering modern-style identifications to substitute what were seen as the old mystifications of consumer culture. It was a poor and empty alternative, however. In attacking ancestral authority, historical significance, and traditional meaning, the new urban ideology could not put anything substantial in its place. Urban principles were not flawless substitution to rural people in offering identity and providing principles of life. At the individual level, it could not fill spiritual vacancies, and its consumer values and fetishism ideology were inadequate, insufficient, feeble, and shallow; at the public level, it was not an alternative for the traditional laws of rural people.

So, it is same to values of selfishness and materialism. Modernism and urbanization was process imposed on the rural people from above and outside. Its self-proclaimed mission was to revolutionize the rural culture for the common good of the rural autonomous people. For the good of a backward uncivilized people, however, people's commitments to civilization and modernization were heading for depravity and suppression. The consequence was that the rural culture - the real anchor for rural people, namely — could not be able to initiate its own innovation. What developed was a dilemma in which the rural people attempted to perpetuate its marginal status with prohibiting both cultural innovation and the autonomy of civil society. Repression was conducted in the name of future prosperity and great dream. Real aspirations and initiatives had to be obstructed because they violated the path of modernization and urban rationalization. The new rural society was basically/negatively fragmented, and there was no place for positive cultural diversities and differences. Substantial diversities in cultural identity were compressed into a single modern representation, and thereby the people were excluded, by definition, from the core of cultural creation. The conditions of positive pluralism and heterogeneity necessary to creative rural cultural identity were suffocated and stifled during the process of urbanization.

The vigor of rural popular culture and creative passion was muffled. But, in addition to that, they were treated as barbarians as well as primitives, consequently, the scarcity in them (possible) only is resolved through the cultivation and perfection of civilization, rather than any stale or obsolete values they might possess. The rural cultural identity was considered as the representation of civilized modern values. Defined by modernity, it seems to be a more rational and secular identity. A seemingly reasonable spiritual anchor was produced (through modernization) to compensate for the authentic ones that were being abandoned. The rural people were "others" against which this urbanization was constituting its identity. This kind of "others" was formed by urbanization. The government was endowed with the task of protecting the ideal modernity in order to guard against the brutal encroachments and destruction of barbarians within. So, Beijing government coups dislodged low-class rural people in the winter of 2017. Physical (also soul) eviction and repression became the ultimate path to civilization and modernization. 
Of course, the rural people could never be banished and dislodged throughout. Since the civilization and modernization has to been go forward with the sacrifice and function of these "low-level" rural people. More importantly, Beijing government has been continually suffering from pressure and opposition. The new management policies for the rescue of urban homeless people were issued in May, 1949, but there was a dramatic institutional change after the death of Sun Zhigang in 2003 (a young rural man worked in Guangzhou but was abused by an old disciplinary system for jobless and homeless). The main change is the abolition of the city shelter system and the establishment of new rescue system (Gao Zhonghua, 2009, pp. 86-93; 127-128). This may be a partial and temporary concession to the rights of rural people, though it was primarily about a redistribution of power between the state and rural people.

In 2017-2018, Chinese government launched out lots of rural culture and identity reconstruction measures. The revival of traditional rural folk activities reflected the attempt to restore traditions as civic identity to fill in the rural culture emptiness and reorder identity disorder, particularly among young people who were born in the internet era, by abandoning the ancestral beliefs and historical values. Since early 1980s, great changes have taken place in the rural area, posing problems of urbanization and modernization with great vehemence (and often violence). Chinese rural had an experienced reform and marketization in 1980, to terminate its outdated phase of rural traditional life, and again urbanization emerged in the strategies to normalize the situation (He \& Xue, 2014, p. 126). Under the policies of rural traditional culture rejuvenation, rural traditional folk culture, such as folk Shehuo, square dance, mental rituals, weeding celebrations, and so on, has become a tool to achieving of social cohesion. Rural folk culture was requisitioned as resources pool to staunch ideological fragmentation and centrifugation. The emphasis continued to be on consensus and unification among the rural people, however. As Chen argues, the requisition and compromise perpetuated the emptiness-anti-diversity and secular-anti-creativity - but in an updated face (Chen, 2011, pp. 87-96).

Rural people may undergo a series of adjustments, then, through which the state tries to regain control of the rural culture; through which it has perpetuated its autocratic control of rural society. It has continuously negated the real diversity of rural culture, which it can only be interpreted in terms of social fragmentation, and against which it has stimulated the idealized fantasy of urban consuming and fetishism culture. Rural people have been driven to defined themselves as "outsiders", indicating that the urbanization has created a social environment where rural groups begin to acquire the identity in a face of modernity.

\section{Reconstructing Participatory Autonomy in a Continuing Way}

Finally, I want to discuss the issue of cultural encounters between the rural area and the urban area, and also want to discuss the cultural autonomy between modernity and history. Both are related to reconstruction of rural cultural identity. Rural cultural identity (which is the cement of social integrity in China) has been historically disintegrated by the process of urbanization and modernization as never before, shaped by it in ways that have invariably been repressive and fragmented.

Castells (2010, p. 9) pointed out that defining boundaries - for example, geographic and ideological boundaries - are an important aspect of identity building (in his book The Power of Identity). Now, as rural people confront dramatic changes and experience new void of their cultural identity, the nature of the rural people reaction will be an important issue, especially dealing with the boundaries. Rural people own responses to what is happening could greatly contribute to the development of a more creative and dynamic cultural identity for themselves, especially their attitudes toward the link between history and modernity, which they 
defend their own ideological boundaries as. At the same time, historical curvatures combined with modernity open the door for rural people re-meeting themselves. Historical collative actions and traditional common memories in rural communities are important sources of identity building (He \& Xue, 2014, p. 132). Historical cultures in modern ways could be exploited as a direct source of self-recognition and autonomous tool in people's revolts against unbearable consumerism culture. If rural people could make use of this continuity and combination, then we might see a rejuvenation of rural culture and a participatory autonomy too.

But the real point is that we have to think of rural cultural identity in the continuity of cultural backward in a modern way. What would an identity mean in regress and autonomy? Which kind of history do we need to return? How do they return to history? How do they establish cultural identity autonomy? Isn't it only through the modernity that rural people become aware of who they are and what they stand for? Because cultural identity has a strong tie with the social identity. While social identity is a set of meanings that define one is when he (she) is an occupant of a particular role in society (Burke \& Stets, 2000, pp. 224-237; 2009, pp. 96-97), and it is undergoing a dilemma of modernization and a revival of traditional meaning (Zhao, 2007, pp. 55-63).

Therefore, we must consider rural cultural identity in terms of the relationship between history and modernity: what can happen through the connections between them. How do we return to history depends on how we understand our present time and how we imagine our future. The definitions of the present and the future in fact determine our invoking historical recourses (Zhang Xudong, 2006, p. 3). Particularly, returning to history and tradition is not equal to return to the historical text and details, but reconstruct the continuity of its historical meaning and values framework through rural people own wisdom and their own participation (Zhang Liang, 2009, pp. 10-14). To go back to historical and traditional meaning does not mean the retrogression and stagnation, but go forward. It is an effort to establish rural own cultural and political awareness in the contemporary discourse (Zhang, 2006, p. 4). It is an effort to seek rural own cultural identity autonomy that appeals rural people work and participate together. "The nostalgia of people for images and experience of tradition-bound ways of life is commodified and presented in fabricated enclaves within the city that come for premium" (Mathur, 2014, p. xviii). It would be better to connect Chinese rural traditional culture with modern (mainly western) culture together to stimulate them mutually to absorb each other's merits to make up for each one's shortcomings ( $\mathrm{Zi}, 1987$, p. 452). During connecting history with modernity, connecting rural people's internal wisdom with official promotion, the historical-participatory culture autonomy will be around the corner. Only in this way, not only can the positive, constructive, and creative values of the historical experience be invoked again, but also we can take up again the question of circulation versus line in identity logic.

Ideally, the interaction between history and modernity will trigger and open new possibilities. It will be possible to resolve some more basic identity anxieties and help rural people recognize themselves as one real part of their self-definition and self-verification instead of being a projection or extension of urban culture. Through interaction between tradition and modernity, it is feasible to rebuild an autonomous continuity and consensus, which in turn constitute the basis of rural cultural identity (Zhao, 2007, pp. 55-63; Zhang, 2006, p. 4). Possibility is that the reconstruction of rural cultural identity in urbanization might be enhanced through a process of continuous interaction between historical culture and modern values - a process that requires rural people to view themselves from the perspective of intertextuality (history and modernity), and understand themselves through the prism of its own consciousness in a continuous self-reflexive process. It relates to the invention of tradition as much as to tradition itself, which they oblige us to read not as a reiteration but as "the changing same" (Hall \& Gay, 1996, p. 4). In such a case there will be cultural identity resurrection without 
suppression. The re-invoking of historical and traditional heritage will be emphasized because of the valuable different possibilities it offers; because of the potentials for creative autonomy that it contains.

That is a perfection (ideal). In actual reality, things can be (may) quite difficult and different; the return of history may be easily blocked more by cultural pragmatism. Cultural regress may be characterized by illusions involving the projection of quick success on the history. They may be constrained by cultural pragmatism, denying the possibilities inherent in the historical tradition, and screaming feelings of speculativeism or pragmatism. Therefore, we need to be especially cautious about that attitude. Creative rural cultural identity can be established through interaction between history and modernity, through telling the story shared by rural people, through the accumulation of their autonomous participation.

So what historical heritage do we need to re-invoke? Myths and folk legends, ancestral links and folk songs, folk dances, folk rituals, folktales, and so on, all of them, especially clan system and common ancestral hall ("gongci" in Chinese word) in rural area, play an important role in the development of rural cultural identity by providing it with an ancestral anchor that can be worshiped (He \& Xue, 2014, pp. 126-137; Cohen, 2005 , p. 3). It does not mean that we must deliberately emphasize the particularity and incompatibility of Chinese traditional rural culture and common shared stories. Instead, we must consider the issue of continuity in the discontinuity of historical development and seek a contemporary expression of the historical experience of Chinese modernity. "The markers of tradition-specific practices as motifs are picked up, hence disembedded, from their traditional contexts and remembered in contemporary context which makes them appear more relevant and amenable in the present age of modernity" (Mathur, 2014, p. xix).

The reestablishment of cultural identity of rural people within modernity context implies not a total rejection of traditional ways of leading one's life, but identification of selective and often highly individualizes strategy of making choice and maintaining status through one's traditional lifestyle (Mathur, 2014, p. xix). In addition to that, the restoration of rural cultural identity represents a critical rethinking of the modern economy and an examination of governing power, sowing the seed of hope for a better life. "A revitalized and reinvented clan system organized around extended kinship networks has played a critical role in reconstituting the collective identity of villages" (He \& Xue, 2014, pp. 126-137). All these factors may promote cultural interaction and cultural creation. The source of cultural dynamics is then immediately activated; the potential between history and modernity is reopened.

Now let's re-discuss the continuity of history (tradition) and modernity with considering the predicament of rural cultural identity. Rural cultural identity is precisely in terms of refuse to the historical tradition and over-openness to modernity. The problem lies in the fact that, in order to remove dependence, the self-sufficient of rural cultural identity needs to be different form modernity. Encountering with the realities of rural culture, there is arrogant indifferent to tradition: disinterest or disdain to tradition that is a main cause of losing self-identity. In refusing to recognize the traditional values and heritage of rural society-in misunderstanding them in terms of feudal, benighted, and superstitious features - they undermine the potentials of creative change (Cohen, 2005, p. 3). Actually, they exerted power on factors that would identify with urbanization (like abandoning historical values and traditional lifestyle), defining what they are in opposition to the historical heritage. For seeking innovations and creativity in historical and traditional heritage, the ruthlessness of the rural cultural outlook is the fundamental obstacle.

In the process of urbanization, rural cultural identity could not come to see itself as self-identical and self-sufficient. So, it has been instituted in discontinuity with the traditional culture and historical heritage. 
Other influences, especially historical ancestral culture, have been dispelled from the everyday rural life. The positivity of rural culture was defined against the image of "non-history". During its expansion, urban self-sufficient culture appeared vibrant, and had achieved a significant progress within the homogenizing (and fragmenting) rural cultural identity. But such progress and achievement will no longer continue. Modernity and urbanization are deteriorating, which are inadequate for new identity needs. Some, having rejected that tradition, are unable to replace it with an alternative cultural arrangement for rural people that provide a satisfactory form of identification (Cohen, 1991, p. 113). In constructing new cultural identity, it is seeking to exclude those who are outdated because of their historical origins and traditions.

Historically, the traditional vitality has been transformed into "an outdated existence, a negative passion, a repulsion". Rural cultural identity today lost its own core in breaking up with history and in rejection of traditions; it hardly has a positive foundation and a solid root any more. The only foundation is to be found in perpetuation of the dialogue (or continuity) between tradition and modernity. After all, "the meaning of modernity is the productions through social, economical and cultural contexts and that it is generated out of different ways in which tradition and modernity get juxtaposed each other...modernity presents new ways of casting and interpreting tradition" (Mathur, 2014, p. xvii). There does not have any other resolution to manage crises of rural cultural identity, except that rural people autonomously participate in telling their own stories and rebuild their own shared-common culture (namely, a consensus of shared behavior, institutions, and beliefs) in the regression with forward (Cohen, 1991, p. 114).

It is a denial of the historical heritage, which is conceived as a kind of regression or hindrance. Particularly, all superstitious sects and traditional societies were banned after the land reform in 1949, but the communist states are unable to give people viable cultural expression from socialism culture in competition with consumerism culture. Before 1949, under the governmentality of family and country gentleman, rural culture were a self-organized unit based on blood and geographical link. However, the building of a new socialist society integrated rural community into modern nation-state plan. Since then, rural culture has been transformed from the self-supply mechanism to the other-supply model (Wu Miao, 2007, pp. 108-112). Therefore, there had already emerged a major crisis of cultural identity after 1990s (Wang Chengbing, 2004, p. 97); rural cultural identity crises are not even an exception. Chinese rural people today identity themselves as a modern Chinese without the cultural support provided by tradition (Cohen, 1991, p. 113).

The indifference of rural traditional culture may be seen in terms of the loss of historical purpose: the end of traditional nourishment. Rural people no longer identify themselves in name of creation of historical tradition. It is no longer open to the determinacy and certainty of the historical process. Traditional rural culture is no longer considered to be a dynamic engine, and also there is no longer a sense of modernity as the source of creativity (Zhao, 2007, pp. 55-63). Post-modernity has become rural people's fashion now, to be cherished and admired rather than reinventing or modifying. There can be no way forward (creation) where there is no sense of the incompletion of history and no continuity between tradition with modernity. There can be no longer change when the sources of change have been negated.

Where once rural people brought the disruption and upheaval of change, now they are blocked and arrested by modernity cage. The rural cultural identity is increasingly become a tricky problem. In a modernization road, history is abandoned in the cultural shoal, resulting in rural people unable to take constructive and creative part of history. It became an urgent anxiety, indeed. People were born from historical continuities, but the stories they are telling themselves about their own lives have suddenly stopped by 
modernity, or become too arduous or painful, or both. It is imperative for rural people that they need to recompose the incomplete stories scripts and restore the loose ends of the history. But what should happen in the case of restore historical ends? What is rural culture identity to do when their traditional story-telling has become painful or arid? The rural problem is of this order; it requires the dialogue, which must be the self-analysis and continuality, of a historical-modern culture.

We cannot be carelessly optimistic. There are no stable foundations for expecting that rural people might mutinously resort themselves to and re-commit themselves to the historical track. Are they actually capable of eradicating its non-traditional perceptions and modern culture desert that surrounds them in terms of independency? In achieving such an autonomy, it would need them to get rid themselves of intoxication with modernity and indifference to tradition, and to summon out what is creative, diverse, and meaningful legacy. It would have to dissipate modernity myths in order to understand the role it has played in destroying and disrupting of their cultural identity and in the disavowal and oppression that have afflicted the tradition. That would mean taking its responsibilities for building a bridge between modernity and tradition. Being on the basses of self-consciousness and self-responsibilities, it would be possible to initiate the interaction and interchange of historical memories with modernity that is necessary to achieve creative reconstruction of cultural identity for rural people (Chen Chujie, Yuan Mengqian, 2011, pp. 87-96).

We cannot go forward if we forget our history. By returning to history and traditional culture, the rural people might be more hopeful to move forward; breaking the daydream and deception of modernity in combination with history, they might rewrite their loose story endings more creatively. If they cannot then recognize the combination between modernity and history, and the possibilities inherent in such a continuity, cannot they rebuild their cultural identity? Cultural identity experience is not only experience of who we are, which is a product of history, but also is the indispensable continuity between modernity and tradition. Stable rural cultural identity can be created out of cultures in relation and interaction with modernity and tradition. Modernity could now play a crucial role in re-historicizing and in re-constructing a satisfactory rural cultural identity, as long we remove the repressive factors. It offers opportunities to unfold the whole change of rural cultural identity in depth, to historical customs, creative values. Moreover, in certain cases, it also provides the possibility to expect what may be achieved on the basis of dialogue between historical values and modern norms. Rural cultural identity must think the essential questions about "what do they want", "who they want to become", and "where do they want to go"; all these are relevant to their continuing self-understanding, self-definition, self-criticism, and self-beyond through combing reinterpretation of tradition with future modern challenges. Without this there is only the restless footprints and rootless anxiety.

\section{References}

Bauman, Z. (2000). Liquid modernity. John Wiley \& Sons. Cambridge (UK): Polity Press.

Berman, M. (1982). All that is solid melts into air: The experience of modernity. New York: Simon \& Schuster.

Bhugra, D. (2004). Migration, distress and cultural identity. British Medical Bulletin, 69(1), 129-141.

Bhugra, D., \& Becker, M. A. (2005). Migration, cultural bereavement and cultural identity. World Psychiatry, 4(1), 18-24.

Burke, P. J., \& Stets, J. E. (2009). Identity theory. New York: Oxford University Press.

Castells, M. (2010). The power of identity: The information age: Economy, society, and culture (2nd ed.). West Sussex (UK): Wiley-Blackwell.

Chen, C. J., \& Yuan, M. Q. (2011). Cultural communication and rural cultural governance: Issues and approaches: An empirical analysis of rural cultural construction in J City of Jiangsu Province. China Rural Observation, 3, 87-96. [In Chinese] 
Chen, Z. J. (2011). Cultural identification and reshaping of the new generation of migrant workers. Theoretical Research, 4, 41-43. [In Chinese]

Cohen, M. L. (1991). Being Chinese: The peripheralization of traditional identity. Daedalus, 120(2), 113-134.

Cohen, M. L. (1993). Cultural and political inventions in modern China: The case of the Chinese "peasant". Daedalus, 122(2), 151-170.

Cohen, M. L. (2005). Kinship, contract, community, and state: Anthropological perspectives on China. Redwood (CA): Stanford University Press.

Gao, Z. H. (2009). From repatriation to rescue management-Changes in the rescue system of urban vagrants and beggars in China[J]. Contemporary China History Studies, 16(06), 86-93; 127-128. [In Chinese]

Hall, S. (1990). Culture identity and diaspora. In J. Rutherford (ed.), Identity. London: Lawrence \& Wishart.

Hall, S., \& Du Gay, P. (Eds.). (1996). Questions of cultural identity. London: Sage Publications.

He, L. P. (2011). Thinking of rural community identity and related issues. People's Forum, 24, 36-37. [In Chinese]

He, S., \& Xue, D. (2014). Identity building and communal resistance against land grabs in Wukan Village, China. Current Anthropology, 55(9), 126-137.

Hoffmann-Axthelm, D. (1992). Identity and reality: The end of the philosophical immigration officer. (J. Polk, Trans. from German). In S. Lasch \& J. Friedman (Eds.), Modernity and identity (pp. 196-217). Oxford: Basil Blackwell.

$\mathrm{Hu}$, H. P. (2009). Reconstruction of rural public cultural identity with "participation"-based on empirical analysis of rural cultural construction in Caidian District of Wuhan City. Journal of Xiamen Party School, 5, 69-73. [In Chinese]

Kellner, D. (1992). Popular culture and constructing postmodern identities. In S. Lasch \& J. Friedman (Eds.), Modernity and identity (pp. 141-177). Oxford: Basil Blackwell.

King, A. D. (Ed.). (1991). Culture, globalization and the world system: Contemporary conditions for the representation of identity (Vol. 3). University of Minnesota Press.

Kneafsey, M. (2001). Rural cultural economy: Tourism and social relations. Annals of Tourism Research, 28(3), $762-783$.

Lefebvre, H. (1970). From rural to urban. Retrieved from https://www.cabdirect.org/cabdirect/abstract/19711801387

Long, H., Zou, J., \& Liu, Y. (2009). Differentiation of rural development driven by industrialization and urbanization in Eastern Coastal China. Habitat International, 33(4), 454-462.

Mathur, N. (Ed.). (2014). Consumer culture, modernity and identity. New Delhi (India): Sage Publications.

Shen, J. F. (2002). A study of the temporary population in Chinese cities. Habitat International, 26, 363-377.

Sofield, T. H., \& Li, F. M. S. (1998). Tourism development and cultural policies in China. Annals of Tourism Research, 25(2), 362-392.

Stets, J. E., \& Burke, P. J. (2000). Identity theory and social identity theory. Social Psychology Quarterly, 224-237.

Sun, F. J. (2009). The cultural destiny of peasant in modern era and their cultural identity reconstruction on the way to new countryside. Socialism Study, 6, 71-75. [In Chinese]

Wang, C. B. (2004). Some ideas on the contemporary identity crisis. Journal of Beijing Normal University (Social Sciences), 4 , 97-99; 107. [In Chinese]

Wang, C. G. (2001). The Relationship between social identity of the new rural immigrants and urban-rural integration. Sociological Study, 3, 63-76. [In Chinese]

Wang, X. M. (2010). Analysis of the dilemma of cultural identity in the practice of rural culture in Hui Villages: A case study of Xiqu Village in Ningxia. Journal of Changji University, 4, 14-18. [In Chinese]

$\mathrm{Wu}$, L. C. (2011). Rural community identity and its reconstruction. Journal of Tianjin Party School, 13(3), 78-84. [In Chinese]

$\mathrm{Wu}, \mathrm{M}$. (2007). On the mode selection of rural culture construction. Journal of Huazhong University of Science and Technology (Social Science Edition), 6, 108-112. [In Chinese]

$\mathrm{Wu}, \mathrm{Q}$. (2015). Analysis of the current situation and countermeasures of rural traditional culture. Eastern Enterprise Culture, 21, 10-12. [In Chinese]

Zhang, L. (2009). The Enlightenment of cultural identity construction in urban community to rural community. Central China Normal University Journal of Postgraduates, 16(01), 10-14. [In Chinese]

Zhang, M. (2004). China's poor regions: Rural-urban migration, poverty, economic reform and urbanisation. New York: Routledge.

Zhang, X. D. (2006). Cultural identity in the era of globalization: A historical critique of western universalist discourse. Bejing (China): Peking University Press. [In Chinese] 
Zhao, J. R. (2006). Identity crisis and nostalgia complex of modern people. Journal of Jinan University (Philosophy and Social Sciences), 28(5), 31-36. [In Chinese]

Zhao, X. D. (2007). The crisis of cultural identity and the politics defined by identity: The antinomy of rural cultural revival. Social Sciences, 1, 55-63. [In Chinese]

$\mathrm{Zi}$, Z. Y. (1987). The relationship of Chinese traditional culture to the modernization of China: An introduction to the current discussion. Asian Survey, 27(4), 442-458. 